\title{
Effect of interaction between occupational stress and polymorphisms of MTHFR gene and SELE gene on hypertension
}

\author{
Fen Yang ${ }^{1}$, Ruiying Qiu ${ }^{1}$, Abudubari Saimaitikari ${ }^{1}$, Ning Tao $^{\text {Corresp., } 1}$, Hengqing An ${ }^{\text {Corresp. } 2}$ \\ ${ }^{1}$ School of Public Health, Xinjiang Medical University, Urumqi, China \\ 2 The First Affiliated Hospital, Xinjiang Medical University, Urumqi Xinjiang, China \\ Corresponding Authors: Ning Tao, Hengqing An \\ Email address: 38518412@qq.com, 13201226586@163.com
}

The G98T polymorphism of SELE gene $\left(c^{2}=6.776, P=0.034\right)$, the C677T $\left(\chi^{2}=7.130\right.$, $P=0.028)$ and A1298C $\left(c^{2}=12.036, P=0.002\right)$ loci of MTHFR gene and the degree of occupational stress ( $c^{2}=11.921, P=0.003$ ) were significantly different between the case group and the control group. The genotypes GT at the G98T polymorphism of the SELE gene $(O R=2.151,95 \% C l: 1.227-3.375)$, and the dominant model(AC/CC versus AA, $\mathrm{OR}=1.925,95 \% \mathrm{Cl}: 1.613-3.816) ; \mathrm{AC}$ and $\mathrm{CC}$ at the $\mathrm{A} 1298 \mathrm{C}$ polymorphism of the MTHFR gene $\left(O R_{A C}=1.917,95 \% C l: 1.064-3.453 ; O R_{C C}=2.233,95 \% C l: 1.082-4.609\right)$, the additive model ( $C C$ versus $A A, O R=2.497,95 \% C l: 1.277-4.883$ ) and the dominant model( $A C / C C$ versus $A A, O R=2.012,95 \% \mathrm{Cl}: 1.200-3.373)$; at the $\mathrm{C} 677 \mathrm{~T}$ polymorphism of the MTHFR gene $C T$ and $\Pi\left(O R_{C T}=1.913,95 \% C l: 1.085-3.375 ; O R_{\Pi}=3.117,95 \% C l: 1.430-6.795\right)$, the additive model (CC versus $\mathrm{AA}, \mathrm{OR}=1.913,95 \% \mathrm{Cl}$ : 1.085-3.375) and the dominant model( $A C / C C$ versus $A A, O R=2.012,95 \% C l: 1.200-3.373)$, which could increase hypertension risk $(P<0.05)$. The gene-gene interaction showed that there was a positive interaction between the A1298C and C677T sites of the MTHFR gene, and the geneoccupational stress interaction showed that there was a positive interaction between the A1298C and C677T sites of the MTHFR gene and the occupational stress. [Conclusion] The interaction of gene mutation and occupational stress in Xinjiang oil workers maybe increase the risk of hypertension. 


\title{
1 Effect of interaction between Occupational stress and
}

2 Polymorphisms of MTHFR Gene and SELE Gene on

3 Hypertension

4

5

6

7

8

9

10

11

12

\author{
Fen Yang ${ }^{1}$, Ruiying Qiu ${ }^{1}$, Abudubari Saimaitikari ${ }^{1}$, Ning Tao ${ }^{1 *}$, Hengqing An $^{2 *}$ \\ ${ }^{1}$ School of Public Health, Xinjiang Medical University, Urumqi Xinjiang, China \\ ${ }^{2}$ The First Affiliated Hospital, Xinjiang Medical University, Urumqi 830011, China \\ * Both authors contributed equally to this work \\ Corresponding Author: \\ XinYi Road, Urumqi, Xinjiang Uygur Autonomous Region. Zipcode: 830011, China. \\ Email address: email: Ning Tao: 38518412@qq.com; Hengqing An: 13201226586@163.com
}

\section{Abstract}

[Background] Gene-environment interaction is related to the prevalence of hypertension, but the impact of genetic polymorphisms on hypertension may vary due to different geography and population.

[Objective] To explore the impact of the interaction among occupational stress and MTHFR gene and SELE gene polymorphism on the prevalence of hypertension in Xinjiang oil workers.

[Methods] A case-control study was conducted on 310 oil workers. In an oilfield base in Karamay City, Xinjiang, 155 hypertensive patients aged 18 60 years old with more than one year of service were selected as the case group, and 155 oil workers without hypertension were selected as the control group according to the 1:1 matching principle (matching conditions: the gender and shift were the same. The age is around 2 years old). The Occupational Stress Scale was used to evaluate the degree of occupational stress, PCR technique was used to detect MTHFR and SELE gene polymorphism, Logistic regression analysis was used to analyze the effects of gene and occupational stress on hypertension, and gene-gene and gene-environment interactions were analyzed by generalized multi-factor dimension reduction method.

[Results] The G98T polymorphism of SELE gene $\left(\chi^{2}=6.776, P=0.034\right)$, the C677T $\left(\chi^{2}=7.130\right.$, $P=0.028)$ and A1298C $\left(\chi^{2}=12.036, P=0.002\right)$ loci of MTHFR gene and the degree of occupational 
35

36

37

38

39

40

41

42

43

44

45

46

47

48

49

50

51

52

53

54

55

56

57

58

59

60

61

62

63

64

65

66

stress $\left(\chi^{2}=11.921, P=0.003\right)$ were significantly different between the case group and the control group. The genotypes GT at the G98T polymorphism of the SELE gene (OR=2.151, 95\%CI: 1.227-3.375), and the dominant model( $\mathrm{AC} / \mathrm{CC}$ versus $\mathrm{AA}, \mathrm{OR}=1.925,95 \% \mathrm{CI}: 1.613-3.816$ ); $\mathrm{AC}$ and $\mathrm{CC}$ at the $\mathrm{A} 1298 \mathrm{C}$ polymorphism of the MTHFR gene $\left(O R_{\mathrm{AC}}=1.917,95 \% C I: 1.064-3.453\right.$; $\left.O R_{\mathrm{CC}}=2.233,95 \% C I: 1.082-4.609\right)$, the additive model (CC versus AA, $\mathrm{OR}=2.497,95 \% C I: 1.277$ 4.883) and the dominant model $(\mathrm{AC} / \mathrm{CC}$ versus $\mathrm{AA}, \mathrm{OR}=2.012,95 \% \mathrm{CI}: 1.200-3.373)$; at the C677T polymorphism of the MTHFR gene CT and TT $\left(O R_{\mathrm{CT}}=1.913,95 \% C I\right.$ : $1.085-3.375$; $\left.O R_{\mathrm{TT}}=3.117,95 \% C I: 1.430-6.795\right)$, the additive model (CC versus AA, OR=1.913, 95\%CI: $1.085-$ 3.375) and the dominant model( $\mathrm{AC} / \mathrm{CC}$ versus $\mathrm{AA}, \mathrm{OR}=2.012,95 \% C I$ : 1.200-3.373), which could increase hypertension risk $(P<0.05)$. The gene-gene interaction showed that there was a positive interaction between the A1298C and C677T sites of the MTHFR gene, and the geneoccupational stress interaction showed that there was a positive interaction between the A1298C and C677T sites of the MTHFR gene and the occupational stress.

[Conclusion] The interaction of gene mutation and occupational stress in Xinjiang oil workers maybe increase the risk of hypertension.

\section{Introduction}

High systolic blood pressure is a leading cause of death from ischemic heart disease, found in Global Burden of Disease Study 2019 (GBD 2019 risk factors collaborators, 2020). Therefore, the effective prevention and control of hypertension in the population has become a major public health issue. Data from a cardiovascular disease risk screening study of 170,000 urban and rural residents showed that the detection rate of age-specific hypertension in people aged 35-75 was as high as 37\% ( Lu et al., 2017). However, the etiology of hypertension is complex and diverse, and has not yet been comprehensively studied. It has been shown that genetic and environmental interactions result in an increased risk of developing hypertension (Huang et al., 2019; Kokubo et al., 2019). Heritability studies have confirmed that genetic variation among individuals with hypertension accounts for approximately $30-60 \%$ of the variation (Liu et al., 2015). In recent years, a number of investigators have focused on the association of MTHFR gene (McNulty et al., 2017) SELE gene (Liao et al., 2016) polymorphisms with hypertension, but the findings have been inconsistent. Evidence from both the GWAS ( $\mathrm{Lu}$ et al., 2015) and epidemiological studies (Amenyah et al., 2020; Ji et al., 2019) suggests that MTHFR gene polymorphisms are associated with the risk of developing hypertension, but polymorphisms at the C677T and A1298C loci of 
67 the MTHFR gene are not consistent in all populations. A case-control study in Orléans found that 68 the prevalence of hypertension in the Algerian population was not associated with the MTHFR 69 gene (Amrani-midoun et al., 2016). Many studies have also confirmed that subjects carrying the 70 677CC genotype are at significantly increased risk of developing hypertension, while the C677T 71 gene polymorphism leads to lower blood pressure (Ghogomu et al., 2016). Meta-analysis suggests 72 that carriers of the $\mathrm{C}$ allele of the A561C polymorphism of the SELE gene may contribute to an 73 increased risk of hypertension in the Chinese Han population (Ouyang et al., 2015). In addition, a 74 significant association between G98T polymorphism and hypertension has also been found (Chen 75 et al., 2008). From this it is clear that the probability of developing cardiovascular risk varies 76 geographically due to genetic polymorphisms. Oil workers in Karamay, Xinjiang, are often 77 associated with the occurrence of occupational stress due to the nature of their special occupation, 78 which in turn affects their physical and mental health. A number of studies have now shown that occupational stress may cause an increase in blood pressure through the neurological response of individuals (Tao et al., 2018).

Therefore, considering the variation in the results of studies conducted in different populations, this study will comprehensively investigate the effects of the interaction among MTHFR gene and SELE gene polymorphisms and occupational stress on hypertension, that aim to provide new ideas for the prevention and control of hypertension in oil workers.

\section{Materials \& Methods}

\section{Study Subjects}

In the case-control study, a total of 183 oil workers with hypertension according to the results of physical examination in 2020 at the central hospital in Karamay, excluding 28 people with incomplete information (missing questionnaire information, no blood samples, low DNA extraction concentration, etc.), and finally including 155 hypertensive patients aged between 1860 years with 1 year of work experience as the case group, and 155 non-hypertensive patients were selected as the control group according to the 1:1 matching principle with gender, age ( \pm 2 years), and shift status as matching factors. All participants signed a written informed consent. The study was approved by the Ethics Review Committee of the First Affiliated Hospital of Xinjiang Medical University (No. 2015006).

\section{Methods}

\section{General Information and Occupational Stress Survey}

A structured questionnaire was used to collect information on gender, age, educational level, shift work, smoking and alcohol consumption (Smoker: smoking $\geq 1$ cigarette per day for six months 
101 or more; drinker: drinking $\geq 2$ times a week with alcohol intake $\geq 50$ g per drinking session 102 regularly $\geq 1$ year (Xing et al., 2018)), marital status, working age, personal income per month and 103 BMI among oil workers. Among them, the Occupational Stress Inventory Revised Edition (OSI104 R) was used to assess the level of occupational stress. The scale consists of the Occupational Role 105 Questionnaire (ORQ), the Personal Strain Questionnaire (PSQ), and the Personal Resources 106 Questionnaire (PRQ). The occupational stress of oil workers in this study was assessed by the 107 ORQ, which consists of six dimensions with 10 entries in one dimension and using a scale of 1 to 1085 and summarized, with higher ORQ scores representing higher levels of occupational stress. 109 According to the scoring principle of the scale, occupational stress was classified as: "Low" 110 (ORQ>160), "Middle" $(120 \leq \mathrm{ORQ} \leq 160)$, and "High" $(\mathrm{ORQ}<120)$.

\section{Diagnosis of hypertension and diagnostic criteria}

112 Blood pressure was measured by a professional physician at the Karamay Central Hospital during 113 a routine physical examination of the oil workers. After the oil workers rested for $10 \mathrm{~min}$, blood 114 pressure was measured twice at $5 \mathrm{~min}$ intervals using a zeroed standard mercury 115 sphygmomanometer to take the mean value, and when the difference was greater than $5 \mathrm{mmHg}$, 116 the mean value was taken after the third measurement. In this study, hypertension was defined 117 according to the Chinese Guidelines for the Prevention and Treatment of Hypertension (2018 118 revision)(Chinese Journal of Cardiovascular Medicine, 2019) as (1) systolic blood pressure (SBP) $119 \geq 140 \mathrm{mmHg}$ and/or diastolic blood pressure (DBP) $\geq 90 \mathrm{mmHg}$ and (2) self-reported hypertension 120 diagnosed by a physician, and being treated with antihypertensive therapy within the past two 121 weeks.

\section{Sample collection}

$1234 \mathrm{ml}$ venous blood sample was collected from each subject after $8 \mathrm{~h}$ fasting period. The samples 124 were put into the ethylenediaminetetraacetic acid (EDTA) anticoagulation tubes. The serum and 125 plasma were separated by centrifugation at $4^{\circ} \mathrm{C}, 8000 \mathrm{r} / \mathrm{min}(20 \mathrm{~mm}$ radius $)$, for $3 \mathrm{~min}$, and then 126 stored at $-20^{\circ} \mathrm{C}$ for future and used to extract the genomic deoxyribonucleic acids (DNAs) and 127 ribonucleic acids (RNAs).

\section{Genotyping method of MTHFR and SELE gene polymorphisms}

129 DNA in blood was quantified using spectrophotometric analysis, and a polymerase chain reaction130 restriction fragment length polymorphism (PCR-RELP) technique to amplify the target fragment 131 and digest the PCR amplified product with specific endonucleases for SNP typing, As follow:

132 First, the genomic DNA was extracted using a TIANamp Blood DNA Kit (TIANGEN, China) in 133 accordance with the manufacturer's instructions. Microspectrophotometer was used to detect the 134 concentration and purity of the DNA samples for the subsequent experiments. Concentration $>100$ 
$135 \mu \mathrm{g} / \mu \mathrm{l}, 1.70<260 \mathrm{OD} / 280 \mathrm{OD}<2.0$ means that the sample is qualified. Second, all DNA samples 136 were genotyped through polymerase chain reaction (PCR)-ligase detection reaction. Table 1 137 presents the primers and restriction endonuclease for amplifying the PCR of the target SNPs for each 138 participant.

139

\section{Statistical analysis}

141 Comparison of rates and genotypes between groups for each polymorphism were performed using 142 chi-square tests, all in SPSS 25.0. SHEsis software was used for Hardy-Weinberg equilibrium test.

143 The effect of each gene polymorphism and occupational tension on hypertension was analyzed by 144 logistic regression, and forest plots were drawn with R. Gene-gene and gene-occupational tension 145 interactions were modeled by applying generalized multifactor downscaling (GMDR) software, 146 and dendrograms were drawn with Multifactor dimensionality reduction (MDR) method.

147

148 Results

149 Distribution of basic demographic characteristics of the case and control groups

150 In this study, 310 oil workers (155 in the case group and 155 in the control group) were 151 investigated, of whom 200 were male and 110 were female in Table 2. The comparison of 152 hypertension among demographic characteristics showed that the differences between different 153 personal income per month $\left(\chi^{2}=5.684, P=0.017\right)$, smoking $\left(\chi^{2}=27.01, P<0.001\right)$, drinking alcohol $154\left(\chi^{2}=8.903, P=0.003\right)$, and BMI $\left(\chi^{2}=5.845, P=0.016\right)$ were statistically significant, while the 155 differences between different ethnic group, educational level, professional title, marital status, and 156 working age groups were not statistically significant $(P>0.05)$.

157 Distribution of SELE and MTHFR genotypic loci and occupational stress between the case 158 group and control group

The distribution of SELE and MTHFR genotype loci and occupational stress degree between the case group and the control group is shown in Table 3. Hardy-Weinberg genetic balance test showed that the distribution of G98T and A561C loci of SELE gene, A1298C and C677T loci of MTHFR gene were consistent with expected values in case group and control group. The G98T polymorphism of SELE gene $\left(\chi^{2}=6.776, P=0.034\right)$, the C677T $\left(\chi^{2}=7.130, P=0.028\right)$ and A1298C $\left(\chi^{2}=12.036, P=0.002\right)$ loci of MTHFR gene and the degree of occupational stress $\left(\chi^{2}=11.921\right.$, $P=0.003$ ) were significantly different between the case group and the control group. 
168

169

170

171

172

173

174

175

176

177

178

179

180

181

182

183

184

185

186

187

188

189

190

191

192

193

194

195

196

197

198

199

200

201

Logistic regression analysis of the relationship between genetic and occupational stress with hypertension

The association of SELE and MTHFR genes and occupational stress with hypertension was analyzed using binary logistic regression and is shown in Table 4. After adjusting for personal income per month, smoking, drinking alcohol, and BMI, genotypes GT at the G98T polymorphism of the SELE gene $(O R=2.151,95 \% C I: 1.227-3.375)$, and the dominant model(AC/CC versus AA, $\mathrm{OR}=1.925,95 \% C I: 1.613-3.816) ; \mathrm{AC}$ and $\mathrm{CC}$ at the A1298C polymorphism of the MTHFR gene $\left(O R_{\mathrm{AC}}=1.917,95 \% C I: 1.064-3.453 ; O R_{\mathrm{CC}}=2.233,95 \% \mathrm{CI}: 1.082-4.609\right)$, the additive model (CC versus $\mathrm{AA}, \mathrm{OR}=2.497,95 \% \mathrm{CI}$ : 1.277-4.883) and the dominant model(AC/CC versus $\mathrm{AA}$, $\mathrm{OR}=2.012,95 \% \mathrm{CI}: 1.200-3.373$ ); at the C677T polymorphism of the MTHFR gene CT and TT $\left(O R_{\mathrm{CT}}=1.913,95 \% C I: 1.085-3.375 ; O R_{\mathrm{TT}}=3.117,95 \% C I: 1.430-6.795\right)$, the additive model (CC versus $\mathrm{AA}, \mathrm{OR}=1.913,95 \% \mathrm{CI}: 1.085-3.375)$ and the dominant model(AC/CC versus $\mathrm{AA}$, $\mathrm{OR}=2.012$, 95\%CI: 1.200-3.373), which could increase hypertension risk $(P<0.05)$.

\section{Effect of gene-gene and gene-occupational tension interactions on hypertension}

GMDR software was used to analyze the effects of gene-gene and gene-occupational tension interactions on hypertension. The gene-gene interaction showed the best interaction model between the MTHFR gene A1298C and C677T loci with a training set precision of 0.6677 and a test set precision of 0.6639 , a sign test $P=0.001$, and a cross-validation agreement coefficient of 10/10, as shown in Table 5 and Figure 1. the dendrogram showed a strong positive interaction between the MTHFR gene A1298C polymorphism and the C677T loci, see Figure 2. The geneoccupational tension interaction showed the best interaction model between MTHFR gene A1298C polymorphism, C677T polymorphism and occupational tension with a training set precision of 0.7662 , test set precision of 0.7440 , sign test $P=0.001$, and cross-validation consistency coefficient of $10 / 10$, see Figure 3. The dendrogram showed a strong positive interaction between the C677T polymorphism of the MTHFR gene and occupational tension, see Figure 4.

\section{Discussion}

Hypertension is a major risk factor for cardiovascular disease and has a low control rate due to its complex and diverse etiology (Gheorghe et al., 2018). Many researchers have done numerous studies on environmental and genetic aspects and found that occupational stress is one of the risk factors for hypertension, but MTHFR gene and SELE base polymorphisms may lead to different levels of individual susceptibility to hypertension depending on geographical regions and ethnicity. Previous studies have also suggested the utility of hypertension susceptibility genotypes

Peer] reviewing PDF | (2021:08:64922:3:0:NEW 11 Jan 2022) 
202 in Mendelian randomization (Fu et al., 2019). However, it has been argued that a single genotype 203 in the MTHFR gene and SELE gene should not be used as independent markers in a Mendelian 204 randomization design, but rather the study should be expanded to include gene-environment 205 interactions. Therefore, this study not only explored the effect of genes, but also the effect of gene206 environment interactions on hypertension.

207 Studies about some populations in the three northeastern provinces of China have found that 208 polymorphisms in the MTHFR genes A1298C and C677T are not significantly associated with 209 hypertension (Liu et al., 2019). In this case-control study of oil workers in Karamay, Xinjiang, 210 adjusting for confounding factors, mutant genes at the A1298C polymorphism and the C677T 211 polymorphism of the MTHFR gene were found to be susceptible genotypes for hypertension, 212 which is consistent with the findings of and Alghasham et al (2012). The human MTHFR gene is 213 located on chromosome 1 (1P36.3) and has 11 exons, and the SNP sites that have a greater impact 214 on enzyme activity are found at the C677T and A1298C loci, which are in the coding region.

215 The C677T polymorphism is a point mutation at the position 677 on MTHFR gene with the 216 substitution of cysteine to thymine nucleotide at that position. This point mutation causes the 217 substitution of alanine to valine in the MTHFR enzyme. The single nucleotide polymorphism of 218 this gene reduces the thermostability of the MTHFR enzyme due to the decreased activity of the 219 enzyme at $37^{\circ} \mathrm{C}$ or higher. MTHFR enzyme activity in homozygous subjects is $50-60 \%$ lower at $22037^{\circ} \mathrm{C}$ and $65 \%$ lower at $46^{\circ} \mathrm{C}$ compared with normal non-mutated controls (Rosenberg et al., 2002).

221 The inability of the MTHFR enzyme to catalyse the conversion of 5,10-methylenetetrahydrofolate 222 to 5-methyltetrahydrofolate leads to the rise of plasma homocysteine levels in the homozygous 223 mutated subjects. Some researchers postulated that homocysteine could cause atherogenesis and 224 thrombogenesis leading to substantialfibrosis and muscle cell hyperplasia, which in turn can be 225 a risk factor for coronary artery disease (Stanger et al., 2004). In addition, The MTHFR C677T 226 227 228 229 230 polymorphism was also reported to be associated with increased risk of myocardial infarction in young/middle-aged Caucasians. Individuals with the MTHFR 677TT genotype and a low folate status had a significantly higher risk of coronary heart disease. A recent study also reported the association between MTHFR C677T gene polymorphism and essential hypertension which is closely related to the increased level of Hcy (Ren et al., 2018).

The present study also yielded such results. Numerous studies have confirmed that homocysteine ( $\mathrm{HCY})$ is an independent risk factor for cardiovascular disease and can cause vascular lesions in the body, and HCY accumulation caused by MTHFR mutations may increase 235 the risk of vascular complications in hypertensive patients. Scholars have demonstrated that HCY levels are significantly elevated in individuals carrying the 677TT genotype, suggesting that the 
236

237

238

239

240

241

242

243

244

245

246

247

248

249

250

251

252

253

254

255

256

257

258

259

260

261

262

263

264

265

266

267

268

269

mechanism of MTHFR C677T and the development of hypertension maybe related to abnormal HCY metabolism due to decreased mutant enzyme activity, which impairs the normal biological function of endothelial cells, thereby inducing oxidative stress that exacerbates the inflammatory response and puts the blood vessels in a persistent inflammatory state, etc. It has been suggested that the A1298C mutation does not inherently affect blood pressure levels but may play a regulatory role when individuals are accompanied by the MTHFR C677T mutation. In contrast, the present study showed that the mutant gene at the A1298C polymorphism of the MTHFR gene is a susceptible genotype for hypertension, which may be due to different geographical and ethnic differences.

When the A-C mutation occurs in the A1298C polymorphism, the transcriptionally expressed glutamate will be converted to alanine, which will affect the catalytic regulation of the enzyme. A case-control study found the A1298 C polymorphisms were related to depression severity (Chen et al., 2021). It has been suggested that although the A1298C mutation itself does not affect blood pressure levels, it may play a regulatory role when individuals are accompanied by the MTHFR C677T mutation. In contrast, the present study showed that the mutated gene with the A1298C polymorphism in the MTHFR gene is a susceptible genotype for hypertension, which may be due to differences across geography and ethnicity. The difference in the association of C677T and A1298C with hypertension may be due to their gene polymorphism, with the C677T mutation site present in the MTHFR gene The C677T mutation site is found in exon 4 of the MTHFR gene and is involved in encoding the catalytic structural domain of the N-terminal part of the enzyme, which directly affects the catalytic activity of the enzyme, whereas the A1298C mutation site is found in exon 7 of the MTHFR gene and encodes the C-terminal regulatory domain.

The study also found that the mutant gene at the G98T polymorphism of the SELE gene was the susceptible genotype for hypertension, which is consistent with the study of Yesheng Wei et al (2003). The human SELE polymorphism, located on the long arm of chromosome 1, is a 13-kb DNA sequence that is a vascular endothelial adhesion molecule and is a marker of vascular endothelial function. Activation of the endothelium promotes atherosclerosis reduces the elasticity of the arterial wall and alters the responsiveness of the endothelium to vascular stimuli, and endothelial dysfunction maybe a major cause of hypertension. The G98T polymorphism is a single nucleotide polymorphism in the coding region caused by the mutation of $\mathrm{G}$ to $\mathrm{T}$ in the $5^{\prime}$ untranslated region of exon 2 of the E-selectin gene at the site 98 (98bp downstream of the transcription start site). It was found that $\mathrm{T}$ allele carriers are at high risk of hypertension and have high blood pressure values. The G98T polymorphism mutation can enhance the expressed SELE function by affecting the E-selectin $5^{\prime}$ untranslated region structure, thus causing enhanced 
270 adhesion, which in turn causes an inflammatory response, damage to endothelial cells, inhibition 271 of NO and prostaglandin production, and diminished vascular responsiveness to endothelium272 dependent vasotransfer substances, resulting in increased vascular resistance and, consequently, 273 hypertension (Qiu et al., 2019; Srivastava et al., 2018). There are fewer studies on SELE gene 274 polymorphisms in other diseases. The SELE gene also appears to be associated with 275 atherosclerosis, with monocytes adhering to vascular endothelial cells and migrating into the 276 endothelium to take up lipids and transform into foam cells as an early event in the formation of 277 atherosclerosis. Early events in the formation of atherosclerosis. Whereas there is no association 278 between A561C gene polymorphism and hypertension. The differences between these studies may 279 be due to epigenetic mechanisms involved in gene expression influenced by environmental 280 conditions (e.g., lifestyle and diet).

281

282

283

284

285

286

287

288

289

290

291

292

293

294

295

296

297

298

299

300

301

302

303

A Meta-study in a population of pregnant women found that the risk of hypertension was significantly increased in the presence of high air pollution and mutations in the MTHFR gene (Yang et al., 2018), and a study by Fu et al. in Chinese children confirmed that there was also an interaction between the MTHFR gene and the effect of obesity on hypertension (Fu et al., 2018). $\mathrm{Wu}$ Chuanyun et al. showed that the interaction between internal environmental factors may be a potential factor contributing to elevated blood pressure (Wu et al., 2015). In this study, we used GMDR software to construct risk models for the effects of gene-gene and gene-environment associations on hypertension, and further analysis of the interactions between occupational stress and the MTHFR and SELE genes found strong positive between the A1298C polymorphism of the MTHFR gene and the C677T polymorphism, and between the C677T polymorphism of the MTHFR gene and occupational stress Taylor et al. (2010) did interaction validation of different genes with the environment and came to similar conclusions. The influence of genes on the pathogenesis of hypertension may be the increased deposition of extracellular matrix components and their altered structure or cell-extracellular matrix attachment, which causes structural changes in the arterial wall. In contrast, the MTHFR gene is an important enzyme for folate metabolism, and mutations in the MTHFR gene cause hyperhomocysteinemia and homocystinuria, indirectly affecting changes in human blood pressure (Bayramoglu et al., 2015). SELE gene, on the other hand, plays a key role in the binding of lymphocytes and monocytes to endothelial cells. Its genetic polymorphisms may upregulate gene expression levels and thus affect the biological functions of its proteins. Several lines of evidence have shown that A561C and G98T gene polymorphisms can lead to a significant increase in blood pressure (Farugue et al., 2011). The special nature of oilfield operations, which often involve shift work, job evaluation, and learning new technologies lead to the occurrence of occupational stress as oilfield workers are often faced with loneliness, insomnia, 
304

305

306

307

308

309

310

311

312

313

314

315

316

317

318

319

320

321

322

323

324

325

326

327

328

329

330

331

332

333

334

335

336

337

338

339

340

and depression separated from their families (Yong et al., 2020). When both genetic and environmental factors are present, the risk of developing hypertension increases significantly.

\section{Conclusions}

In conclusion, the risk of hypertension among oil workers in Karamay, Xinjiang, maybe influenced not only by environmental but also by genetic factors, and there is a strong interaction between the two, which provides an updated vision for the prevention and control of hypertension. This study demonstrated a strong interaction between gene-gene and gene-environment effects on hypertension, but there are several potential limitations that should not be overlooked: first, the sample size was small and there may be selection bias. Second, the genotyping method used in this study may have potential bias, and there are reports demonstrating higher sensitivity and accuracy of genotyping methods such as Mass Array and gene chips. Therefore, further sample expansion and selection of more appropriate genotyping methods must be performed in the future to confirm the results we observed in this study.

\section{Acknowledgements}

The authors thank all participants and investigators.

\section{References}

GBD 2019 Risk Factors Collaborators. 2020. Global burden of 87 risk factors in 204 countries and territories, 1990-2019: a systematic analysis for the Global Burden of Disease Study 2019. The Lancet 396(10258):1223-1249 DOI 10.1016/S0140-6736(20)30752-2.

Lu JP, Lu Y, Wang XC, Li XY, Linderman GC, Wu CQ, Cheng XY, Mu L, Zhang HB, Liu JM, Su M, Zhao HY, Spatz ES, Spertus JA, Masoudi FA, Krumholz HM, Jiang LX. 2017. Prevalence, awareness, treatment, and control of hypertension in China: data from 1.7 million adults in a population-based screening study (China PEACE Million Persons Project). The Lancet 390(10112):2549-2558 DOI 10.1016/S0140-6736(17)32478-9.

Huang L, Lian QL, Zhen L, Wei DQ, Wang ZJ. 2019. The influence of interaction between gene and environmental factors on the prevalence of hypertension for the elderly. Strait Journal of Preventive Medicine 2:17-19. DOI CNKI: SUN: HXYF.0.2019-02-006.

Kokubo Y, Padmanabhan S, Iwashima Y, Yamagishi K, Goto A. 2019. Gene and environmental interactions according to the components of lifestyle modifications in hypertension guidelines. Environmental Health and Preventive Medicine 24(1):19. DOI 10.1186/s12199-019-0771-2.

Liu F, He J, Gu D, Rao DC, Huang J, Hixson JE, Jaquish CE, Chen J, Li C, Yang X, Li J, Rice TK, Shimmin LC, Kelly TN. 2015. Associations of Endothelial System Genes with 
341

342

343

344

345

346

347

348

349

350

351

352

353

354

355

356

357

358

359

360

361

362

363

364

365

366

367

368

369

370

371

372

373

374

375

376

377

378

Blood Pressure Changes and Hypertension Incidence: The GenSalt Study. American Journal of Hypertension 28(6):780-788 DOI 10.1093/ajh/hpu223.

McNulty H, Strain JJ, Hughes CF, Ward M. 2017. Riboflavin, MTHFR genotype and blood pressure: A personalized approach to prevention and treatment of hypertension. Molecular Aspects of Medicine 53:2-9 DOI 10.1016/j.mam.2016.10.002.

Liao B, Chen K, Xiong W, Chen R, Mai A, Xu Z, Dong S. 2016. Relationship of SELE A561C and G98T Variants with the Susceptibility to CAD. Medicine 95(8):e1255. DOI 10.1097/MD.0000000000001255.

Lu X, Wang L, Lin X, Huang J, Charles Gu C, He M, Shen H, He J, Zhu J, Li H, Hixson JE, Wu T, Dai J, Lu L, Shen C, Chen S, He L, Mo Z, Hao Y, Mo X, Yang X, Li J, Cao J, Chen J, Fan Z, Li Y, Zhao L, Li H, Lu F, Yao C, Yu L, Xu L, Mu J, Wu X, Deng Y, Hu D, Zhang W, Ji X, Guo D, Guo Z, Zhou Z, Yang Z, Wang R, Yang J, Zhou X, Yan W, Sun N, Gao P, Gu D. 2015. Genome-wide association study in Chinese identifies novel loci for blood pressure and hypertension. Human Molecular Genetics 24(3):865-874.

DOI $10.1093 / \mathrm{hmg} / \mathrm{ddu} 478$.

Amenyah SD, Ward M, McMahon A, Deane J, McNulty H, Hughes C, Strain JJ, Horigan G, Purvis J, Walsh CP, Lees-Murdock DJ. 2020. DNA methylation of hypertension-related genes and effect of riboflavin supplementation in adults stratified by genotype for the MTHFR C677T polymorphism. International of Journal Cardiology 322:233-239. DOI 10.1016/j.ijcard.2020.09.011.

Ji Y, Yiorkas AM, Frau F, Mook-Kanamori D, Staiger H, Thomas EL, Atabaki-Pasdar N, Campbell A, Tyrrell J, Jones SE, Beaumont RN, Wood AR, Tuke MA, Ruth KS, Mahajan A, Murray A, Freathy RM, Weedon MN, Hattersley AT, Hayward C, Machann J, Häring HU, Franks P, de Mutsert R, Pearson E, Stefan N, Frayling TM, Allebrandt KV, Bell JD, Blakemore AI, Yaghootkar H. 2019. Genome -Wide and Abdominal MRI Data Provide Evidence That a Genetically Determined Favorable Adiposity Phenotype Is Characterized by Lower Ectopic Liver Fat and Lower Risk of Type 2 Diabetes, Heart Disease, and Hypertension. Diabetes 68(1):207-219 DOI 10.2337/db18-0708.

Amrani-Midoun A, Kiando SR, Treard C, Jeunemaitre X, Bouatia-Naji N. 2016. The relationship between MTHFR C677T gene polymorphism and essential hypertension in a sample of an Algerian population of Oran city. International of Journal Cardiology 15(225): 408-411 DOI 10.1016/j.ijcard.2016.10.027

Ghogomu SM, Ngolle NE, Mouliom RN, Asa BF. 2016. Association between the MTHFR C677T gene polymorphism and essential hypertension in South West Cameroon. Genetics and Molecular Research 15(1) DOI 10.4238/gmr.15017462

Ouyang Y, Wu H, Tan A, Yang H, Gao Y, Li H, Lu S, Hu Y, Tang X, Zhang H. 2015. Eselectin gene polymorphism (A561C) and essential hypertension, Meta-analysis in the Chinese population. Herz 40 (Supplement 2):197-202 DOI 10.1007/s00059-014-4122-1. 
379

380

381

382

383

384

385

386

387

388

389

390

391

392

393

394

395

396

397

398

399

400

401

402

403

404

405

406

407

408

409

410

411

412

413

414

415

416

417

Chen HL, Hua Q, Guo JC, Xu J, Yang RQ. 2008. Correlation between polymorphism of Eselection G98T and blood pressure in patient with essential hypertension. Journal of Cardiovascular and Pulmonary Diseases 27(1): 16-20+33.

DOI 10.3969/j.issn.1007-5062.2008.01.006.

Tao N, Ge H, Wu W, An H, Liu J, Xu X. 2018. Association of glucocorticoid receptor gene polymorphism and occupational stress with hypertension in desert petroleum workers in Xinjiang, China. BMC Medical Genetics 19(1): 213 DOI 10.1186/s12881-018-0688-4.

Xing HY, Liu Y, Zhao A, Zheng W, Li T, Zheng YD, Wang Y, Zhang YM. 2018. Effects of smoking, drinking and dietary factors on hypertension in subjects with hyperuricemia. Chinese Journal of Disease Control \& Prevention 22(6): 55-559.

DOI 10.16462/j.cnki.zhjbkz.2018.06.004

2019. 2018 Chinese guidelines for the management of hypertension. Chinese Journal of Cardiovascular Medicine 24(1):24-56 DOI 10.3969/j.issn.1007-5410.2019.01.002.

Gheorghe A, Griffiths U, Murphy A, Legido-Quigley H, Lamptey P, Perel P. 2018. The economic burden of cardiovascular disease and hypertension in low- and middle-income countries: a systematic review. BMC Public Health 18(1):975.

DOI 10.1186/s12889-018-5806-X.

Fu L, Li YN, Luo D, Deng S, Wu B, Hu YQ. 2019. Evidence on the causal link between homocysteine and hypertension from a meta-analysis of 40173 individuals implementing Mendelian randomization. The Journal of Clinical Hypertension 21(12):1879-1894. DOI 10.1111/jch.13737.

Liu S, Liu M, Li Q, Liu X, Wang Y, Mambiya M, Zhang K, Yang L, Zhang Q, Shang M, Zeng F, Nie F, Liu W. 2019. Association of single nucleotide polymorphisms of MTHFR, TCN2, RNF213 with susceptibility to hypertension and blood pressure. Bioscience Reports 39(12):BSR20191454 DOI 10.1042/BSR20191454.

Alghasham A, Settin AA, Ali A, Dowaidar M, Ismail H. 2012. Association of MTHFR C677T and A1298C gene polymorphisms with hypertension. International Journal of Health Sciences (Qassim university) 6(1):3-11 DOI 10.12816/0005968.

Rosenberg N, Murata M, Ikeda Y, Opare-Sem O, Zivelin A, Geffen E, Seligsohn U. 2019. The frequent 5,10-methylenetetrahydrofolate reductase C677T polymorphism is associated with a common haplotype in whites, Japanese, and Africans. American journal of human genetics 70(3):758-762 DOI 10.1086/338932.

Stanger O, Herrmann W, Pietrzik K, Fowler B, Geisel J, Dierkes J, Weger M. 2004. Clinical use and rational management of homocysteine, folic acid, and B vitamins in cardiovascular and thrombotic diseases. Zeitschrift fur Kardiologie 93(6): 439-453

DOI 10.1007/s00392-004-0075-3

Ren Y, He Y H, and Cao M J. 2018. Correlation Analysis of MTHFR andMTRR Gene Related Mutations With H Type Hypertension. J. Yan'an U 16(3): 73-76

DOI 10.3969/j.issn.1672-2639.2018.03.021 
418

419

420

421

422

423

424

425

426

427

428

429

430

431

432

433

434

435

436

437

438

439

440

441

442

443

444

445

446

447

448

449

450

451

452

453

Chen DD, Chang R. 2021. Associations of Hcy and the distribution of MTHFR A1298C with essential hypertension in Qinghai Tibetans. Chinese Journal of Clinical Research 34(07):877-880+885 DOI 10.13429/j.cnki.cjcr.2021.07.003

Wei YS, Li Y, Zhang PG, Li XY, Huang CX. 2003. Association of E-selectin exon 2 G98T gene polymorphism with hypertensive disease. Shandong Medical Journal 31:14-15. DOI CNKI: SUN: SDYY.0.2003-31-008.

Qin L, Zhao P, Liu Z, Chang P. 2015. Associations SELE gene haplotype variant and hypertension in Mongolian and Han populations. Internal Medicine 54(3):287-293. DOI 10.2169/internalmedicine.54.2797.

Srivastava K, Chandra S, Narang R, Bhatia J, Saluja D. 2018. E - selectin gene in essential hypertension: a case - control study. European Journal of Clinical Investigation 48:e12868 . DOI 10.1111/eci.12868.

Yang YL, Yang HL, Shiao SPK. 2018. Meta-Prediction of MTHFR Gene Polymorphisms and Air Pollution on the Risk of Hypertensive Disorders in Pregnancy Worldwide. International Journal of environmental Research Public Health 15(2):326 DOI 10.3390/ijerph15020326.

Fu L, Zhang M, Hu YQ, Zhao X, Cheng H, Hou D, Mi J. 2018. Gene-gene interactions and associations of six hypertension related single nucleotide polymorphisms with obesity risk in a Chinese children population. Gene 679: 320-327 DOI 10.1016/j.gene.2018.09.019.

Wu CY, Zhou XM, Dong M, Huang KQ, Xu H, Su Y, Wang L, Chen XG, Zhang HM, Dong CW. 2015. Correlation between AT1R gene polymorphism and environmental factors ang its implication for TCM patterns in essential hypertension. Journal of Beijing University of Traditional Chinese Medicine 38(12):817-822. DOI 10.3969/j.issn.1006-2157.2015.12.005.

Taylor JY, Sun YV, Hunt SC, Kardia SL. 2010. Gene-environment interaction for hypertension among African American women across generations. Biological Research for Nursing 12(2): 149-155 DOI 10.1177/1099800410371225.

Bayramoglu A, Urhan Kucuk M, Guler HI, Abaci O, Kucukkaya Y, Colak E. 2015. Is there any genetic predisposition of MMP-9 gene C1562T and MTHFR gene C677T polymorphisms with essential hypertension? Cytotechnology 67(1):115-122.

DOI 10.1007/s10616-013-9665-0.

Faruque MU, Chen G, Doumatey A, Huang H, Zhou J, Dunston GM, Rotimi CN, Adeyemo AA. 2011. Association of ATP1B1, RGS5 and SELE polymorphisms with hypertension and blood pressure in African-Americans. Journal of Hypertension 29(10):1906-1912. DOI 10.1097/HJH.0b013e32834b000d.

Yong X, Gao X, Zhang Z, Ge H, Sun X, Ma X, Liu J.2020. Associations of occupational stress with job burn-out, depression and hypertension in coal miners of Xinjiang, China: a crosssectional study. BMJ Open 10(7): e036087 DOI 10.1136/bmjopen-2019-036087. 
Table $\mathbf{1}$ (on next page)

Primer sequences

No 
1 Table1 The primers and restriction endonuclease for amplifying the PCR of the target SNPs

\begin{tabular}{|c|c|c|c|c|}
\hline & SELE A 561C & SELE G98T & MTHFR C677T & MTHFR A1298C \\
\hline \multirow{4}{*}{ Primer sequences } & F:ATTAGCATCAAG & F:TGCCCAAAATC & F:TGAAGGAGAGG & F:CTTCTACCTGAAGAG \\
\hline & GTTTAGGATAGGT & TTAGGATGC & TGTCTGCGGGA & CAAGTC \\
\hline & R:TGAAGAAAGAG & R:AAGCCCAGGGA & R:AGGACGGTGCG & R:CATGTCCACAGCATG \\
\hline & AGGCAAGAACCA & AGAACACAT & GTGAGAGTG & GAG \\
\hline Length & $326 \mathrm{bp}$ & $332 \mathrm{bp}$ & $198 \mathrm{bp}$ & $256 b p$ \\
\hline $\operatorname{REE}(\mu \mathrm{l})$ & $\operatorname{PstI}(0.2)$ & HphI(1) & HinfI(1) & MboII(1) \\
\hline 10x Buffer $(\mu \mathrm{l})$ & 2 & 2 & 2 & 2 \\
\hline $\mathrm{ddH} 2 \mathrm{O}(\mu \mathrm{l})$ & 3 & 8.5 & 7 & 7 \\
\hline PCR products & 17 & 8.5 & 10 & 10 \\
\hline Temperature $\left({ }^{\circ} \mathrm{C}\right)$ & 37 & 37 & 37 & 37 \\
\hline Time(min) & 15 & 240 & 10 & 60 \\
\hline Agarose gels & $2.5 \%$ & $2.5 \%$ & $3 \%$ & $3 \%$ \\
\hline \multirow[t]{2}{*}{ Voltage } & $110 \mathrm{~V}$ & $100 \mathrm{~V}$ & $110 \mathrm{~V}$ & $100 \mathrm{~V}$ \\
\hline & CC:326bp & TT:332bp & CC:198bp & CC256bp \\
\hline \multirow[t]{2}{*}{ Genotyping } & AA: $222+104 b p$ & GG:194+138bp & TT:175+23bp & $\mathrm{AA}: 17+22+30+27 \mathrm{bp}$ \\
\hline & $\mathrm{AC}: 326+222+104 b p$ & GT:332+194+138bp & CT:198+175+23bp & $A C: 256+176+22+30+27 b p$ \\
\hline
\end{tabular}

2 
Table 2 (on next page)

\section{Amplification system}

No 
Table 1 Distribution of basic demographic characteristics of case group and control group

\begin{tabular}{|c|c|c|c|c|c|c|c|}
\hline \multirow[t]{2}{*}{ Item } & \multirow[t]{2}{*}{$N$} & \multicolumn{2}{|c|}{ Case group } & \multicolumn{2}{|c|}{ Control group } & \multirow[t]{2}{*}{$\chi^{2}$} & \multirow[t]{2}{*}{$P$} \\
\hline & & $n$ & $\%$ & $n$ & $\%$ & & \\
\hline Gender & & & & & & 0.000 & 1.000 \\
\hline Male & 200 & 100 & 50.0 & 100 & 50.0 & & \\
\hline Female & 110 & 55 & 50.0 & 55 & 50.0 & & \\
\hline Age/years & 310 & \multicolumn{2}{|c|}{$46.20 \pm 5.458$} & \multicolumn{2}{|c|}{$46.21 \pm 5.469$} & 0.010 & 0.992 \\
\hline \multicolumn{6}{|l|}{ Shift work } & 0.000 & 1.000 \\
\hline Yes & 216 & 108 & 50.0 & 108 & 50.0 & & \\
\hline No & 94 & 47 & 50.0 & 47 & 50.0 & & \\
\hline \multicolumn{6}{|l|}{ Ethnic group } & 1.741 & 0.187 \\
\hline Han & 253 & 122 & 48.2 & 131 & 51.8 & & \\
\hline Others & 57 & 33 & 57.9 & 24 & 42.1 & & \\
\hline \multicolumn{6}{|l|}{ Educational level } & 3.780 & 0.052 \\
\hline High school or below & 173 & 95 & 549 & 78 & 45.1 & & \\
\hline College or above & 137 & 60 & 43.8 & 77 & 56.2 & & \\
\hline \multicolumn{6}{|l|}{ Professional title } & 1.229 & 0.268 \\
\hline Junior or below & 95 & 43 & 45.3 & 52 & 54.7 & & \\
\hline Intermediate or above & 215 & 112 & 52.1 & 103 & 47.9 & & \\
\hline \multicolumn{6}{|l|}{ Marital status } & 1.303 & 0.521 \\
\hline Single & 13 & 8 & 61.5 & 5 & 38.5 & & \\
\hline Married & 259 & 126 & 48.6 & 133 & 51.4 & & \\
\hline Divorced/others & 38 & 21 & 55.3 & 17 & 44.7 & & \\
\hline \multicolumn{6}{|c|}{ Personal income per month/Yuan } & 5.684 & 0.017 \\
\hline$<5000$ & 202 & 111 & 55.0 & 91 & 945.0 & & \\
\hline$\geq 5000$ & 108 & 44 & 40.7 & 64 & 59.3 & & \\
\hline \multicolumn{6}{|l|}{ Smoking } & 27.01 & $\square \mathbf{0 . 0 0 1}$ \\
\hline Yes & 183 & 114 & 62.3 & 69 & 37.7 & & \\
\hline No & 127 & 41 & 32.3 & 86 & 67.7 & & \\
\hline \multicolumn{6}{|l|}{ Drinking alcohol } & 8.903 & 0.003 \\
\hline Yes & 218 & 121 & 55.5 & 97 & 44.5 & & \\
\hline No & 92 & 34 & 37.0 & 58 & 63.0 & & \\
\hline \multicolumn{6}{|c|}{ BMI (Body mass index $/ \mathrm{kg} \cdot \mathrm{m}^{-2}$ ) } & 5.845 & 0.016 \\
\hline
\end{tabular}




\begin{tabular}{lccccccc}
\hline $18.5 \sim 24$ & 102 & 41 & 40.2 & 61 & 59.8 & & \\
$>24$ & 208 & 114 & 54.8 & 94 & 45.2 & & \\
Working age/years & & & & & & 1.685 & 0.194 \\
$\quad \leq 15$ & 113 & 51 & 45.1 & 62 & 54.9 & & \\
$>15$ & 197 & 104 & 52.8 & 93 & 47.2 & & \\
$\quad$ Total & 310 & 155 & 50.0 & 155 & 50.0 & & \\
\hline
\end{tabular}

2 
Table 3 (on next page)

Amplification procedure

No 
Table 2 Distribution of gene and occupational stress between case group and control group

\begin{tabular}{|c|c|c|c|c|c|c|c|}
\hline \multirow[t]{2}{*}{ Item } & \multirow[t]{2}{*}{$N$} & \multicolumn{2}{|c|}{ Case group } & \multicolumn{2}{|c|}{ Control group } & \multirow{2}{*}{$\begin{array}{l}\chi^{2} \\
1.025\end{array}$} & \multirow{2}{*}{$\begin{array}{l}P \\
0.599 \\
\end{array}$} \\
\hline & & $n$ & $\%$ & $n$ & $\%$ & & \\
\hline \multicolumn{8}{|l|}{ SELE A561C } \\
\hline AA & 213 & 103 & 48.4 & 110 & 51.6 & & \\
\hline $\mathrm{CC}$ & 15 & 9 & 60.0 & 6 & 40.0 & & \\
\hline $\mathrm{AC}$ & 82 & 43 & 52.4 & 39 & 47.6 & & \\
\hline SELE G98T & & & & & & 6.776 & 0.034 \\
\hline GG & 196 & 87 & 44.4 & 109 & 55.6 & & \\
\hline $\mathrm{TT}$ & 16 & 10 & 62.5 & 6 & 37.5 & & \\
\hline GT & 98 & 58 & 59.2 & 40 & 40.8 & & \\
\hline MTHFR A1298C & & & & & & 12.036 & 0.002 \\
\hline AA & 102 & 37 & 36.3 & 65 & 63.7 & & \\
\hline $\mathrm{CC}$ & 66 & 40 & 60.6 & 26 & 39.4 & & \\
\hline $\mathrm{AC}$ & 142 & 78 & 54.9 & 64 & 45.1 & & \\
\hline MTHFR C677T & & & & & & 7.130 & 0.028 \\
\hline $\mathrm{CC}$ & 116 & 50 & 43.1 & 66 & 56.9 & & \\
\hline TT & 52 & 34 & 65.3 & 18 & 34.6 & & \\
\hline $\mathrm{CT}$ & 142 & 71 & 50.0 & 71 & 50.0 & & \\
\hline Occupational stress & & & & & & 11.921 & 0.003 \\
\hline Low & 23 & 8 & 34.8 & 15 & 65.2 & & \\
\hline Middle & 127 & 52 & 40.9 & 75 & 59.1 & & \\
\hline High & 160 & 95 & 59.4 & 65 & 40.6 & & \\
\hline
\end{tabular}


Table 4 (on next page)

Distribution of basic demographic characteristics of case group and control group 
1 Table3 logistic regression analysis of the influence of genes and occupational stress on the prevalence of 2

\begin{tabular}{|c|c|c|c|c|}
\hline \multirow[t]{2}{*}{ Gene } & \multicolumn{2}{|l|}{ Unadjusted } & \multicolumn{2}{|l|}{ Adjusted } \\
\hline & OR $(95 \% C I)$ & $P$ & $O R(95 \% C I)$ & $P$ \\
\hline \multicolumn{5}{|c|}{ SELE A561C } \\
\hline $\mathrm{AA}$ & 1.00 & & 1.00 & \\
\hline $\mathrm{AC}$ & $1.073(0.624-1.844)$ & 0.800 & $1.161(0.654-2.058)$ & 0.610 \\
\hline $\mathrm{CC}$ & $1.519(0.496-4.652)$ & 0.465 & $1.667(0.495-5.617)$ & 0.409 \\
\hline Additive & $1.751(0.547-5.601)$ & 0.345 & $1.602(0.551-4.658)$ & 0.387 \\
\hline Dominant & $1.243(0.763-1.997)$ & 0.392 & $1.337(0.800-2.235)$ & 0.268 \\
\hline Recessive & $0.653(0.227-1.882)$ & 0.430 & $0.603(0.192-1.896)$ & 0.387 \\
\hline \multicolumn{5}{|l|}{ SELE G98T } \\
\hline GG & 1.00 & & 1.00 & \\
\hline GT & $2.039(1.211-3.433)$ & 0.007 & $2.151(1.227-3.375)$ & 0.008 \\
\hline TT & $2.756(0.924-8.216)$ & 0.069 & $2.724(0.879-8.439)$ & 0.082 \\
\hline Additive & $2.088(0.730-5.971)$ & 0.170 & $2.086(0.666-6.535)$ & 0.207 \\
\hline Dominant & $1.852(1.159-2.959)$ & 0.010 & $1.925(1.163-3.186)$ & 0.011 \\
\hline Recessive & $0.584(0.207-1.648)$ & 0.309 & $0.602(0.199-1.822)$ & 0.369 \\
\hline \multicolumn{5}{|c|}{ MTHFR A1298C } \\
\hline AA & 1.00 & & 1.00 & \\
\hline $\mathrm{AC}$ & $2.223(1.279-3.864)$ & 0.005 & $1.917(1.064-3.453)$ & 0.030 \\
\hline $\mathrm{CC}$ & $2.682(1.351-5.327)$ & 0.005 & $2.233(1.082-4.609)$ & 0.030 \\
\hline Additive & $2.703(1.428-5.114)$ & 0.002 & $2.497(1.277-4.883)$ & 0.007 \\
\hline Dominant & $2.303(1.414-3.752)$ & 0.001 & $2.012(1.200-3.373)$ & 0.008 \\
\hline Recessive & $0.579(0.333-1.008)$ & 0.054 & $0.610(0.337-1.104)$ & 0.103 \\
\hline \multicolumn{5}{|c|}{ MTHFR C677T } \\
\hline $\mathrm{CC}$ & 1.00 & & 1.00 & \\
\hline CT & $1.683(0.990-2.860)$ & 0.054 & $1.913(1.085-3.375)$ & 0.025 \\
\hline TT & $2.511(1.230-5.125)$ & 0.011 & $3.117(1.430-6.795)$ & 0.004 \\
\hline Additive & $2.493(1.264-4.918)$ & 0.008 & $2.936(1.398-6.166)$ & 0.004 \\
\hline Dominant & $1.557(0.980-2.575)$ & 0.061 & $1.802(1.094-2.968)$ & 0.021 \\
\hline Recessive & $0.468(0.251-0.870)$ & 0.017 & $0.437(0.225-0.849)$ & 0.015 \\
\hline \multicolumn{5}{|c|}{ Occupational stress } \\
\hline Low & 1.00 & & 1.00 & \\
\hline Middle & $1.300(0.514-3.289)$ & 0.580 & $0.753(0.277-2.051)$ & 0.579 \\
\hline High & $2.740(1.098-6.837)$ & 0.031 & $1.629(0.610-4.352)$ & 0.330 \\
\hline
\end{tabular}




\section{Table 5 (on next page)}

GMDR model of the influence of gene-gene, gene-occupational stress interaction on the prevalence of hypertension

GMDR model of the influence of gene-gene, gene-occupational stress interaction on the prevalence of hypertension 
Table 4 GMDR model of the influence of gene-gene, gene-occupational stress

2 interaction on the prevalence of hypertension

\begin{tabular}{lcccc}
\hline \multirow{2}{*}{ Interaction model } & \multicolumn{2}{c}{ Accuracy } & Sign test $(P)$ & $\begin{array}{c}\text { CV } \\
\text { consistency }\end{array}$ \\
\cline { 2 - 3 } & Training set & $\begin{array}{c}\text { Testing } \\
\text { set }\end{array}$ & & \\
\hline Gene-Gene & & & & $10 / 10$ \\
A1298C & 0.5903 & 0.5851 & $9(0.0107)$ & $10 / 10$ \\
A1298C*C677T & 0.6677 & 0.6639 & $10(0.0010)$ & $7 / 10$ \\
A1298C*C677T*A561C & 0.6929 & 0.6542 & $10(0.0010)$ & $10 / 10$ \\
A1298C*C677T*A561C*G98T & 0.7310 & 0.6340 & $10(0.0010)$ & $7 / 10$ \\
Gene-Occupational stress & & & & $9 / 10$ \\
Occupational stress & 0.5993 & 0.5503 & $8(0.0547)$ & $10 / 10$ \\
Occupational stress*C677T & 0.7010 & 0.6586 & $10(0.0010)$ & 10 \\
Occupational stress*C677T*A1298C & 0.7662 & 0.7440 & $10(0.0010)$ & $10 / 10$ \\
Occupational stress*C677T*A1298C*G98T & 0.7958 & 0.7351 & $10(0.0010)$ & $10 / 10$ \\
Occupational stress*C677T*A1298C*G98T*A561C & 0.8235 & 0.6916 & $10(0.0010)$ & 10 \\
\hline
\end{tabular}

3 
Figure 1

Forest plot of logistic regression analysis of the influence of genes and occupational

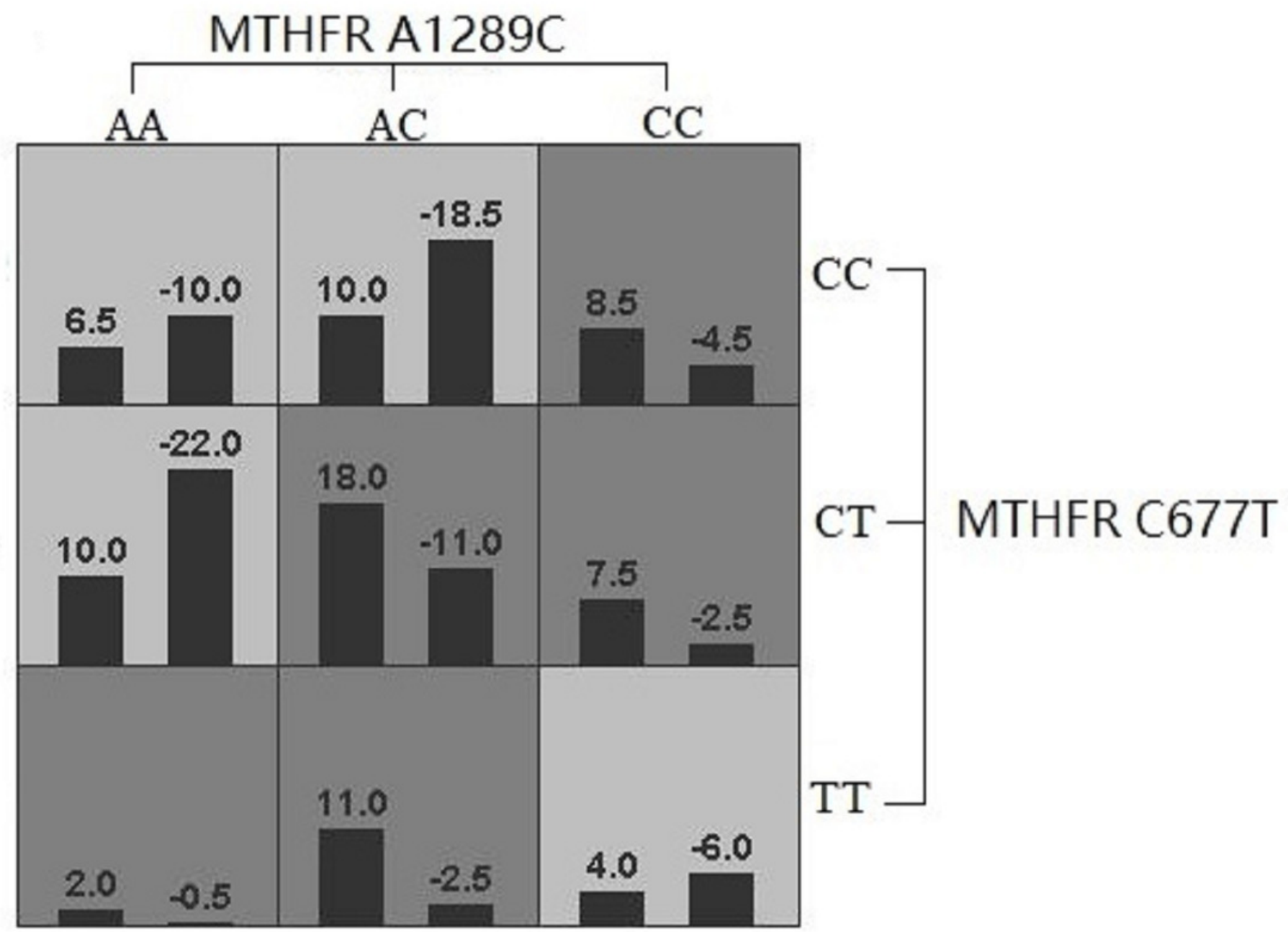


Figure 2

Gene-gene interaction model of MTHFR gene A1298C and C677T sites

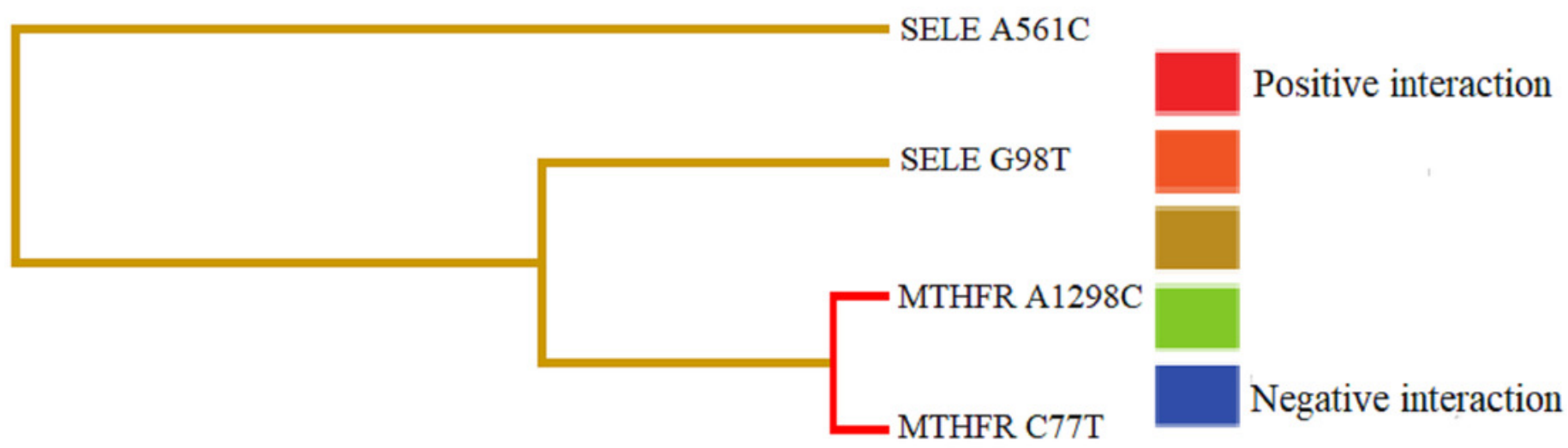


Figure 3

Gene-gene interaction dendrogram of MTHFR gene A1298C and C677T sites

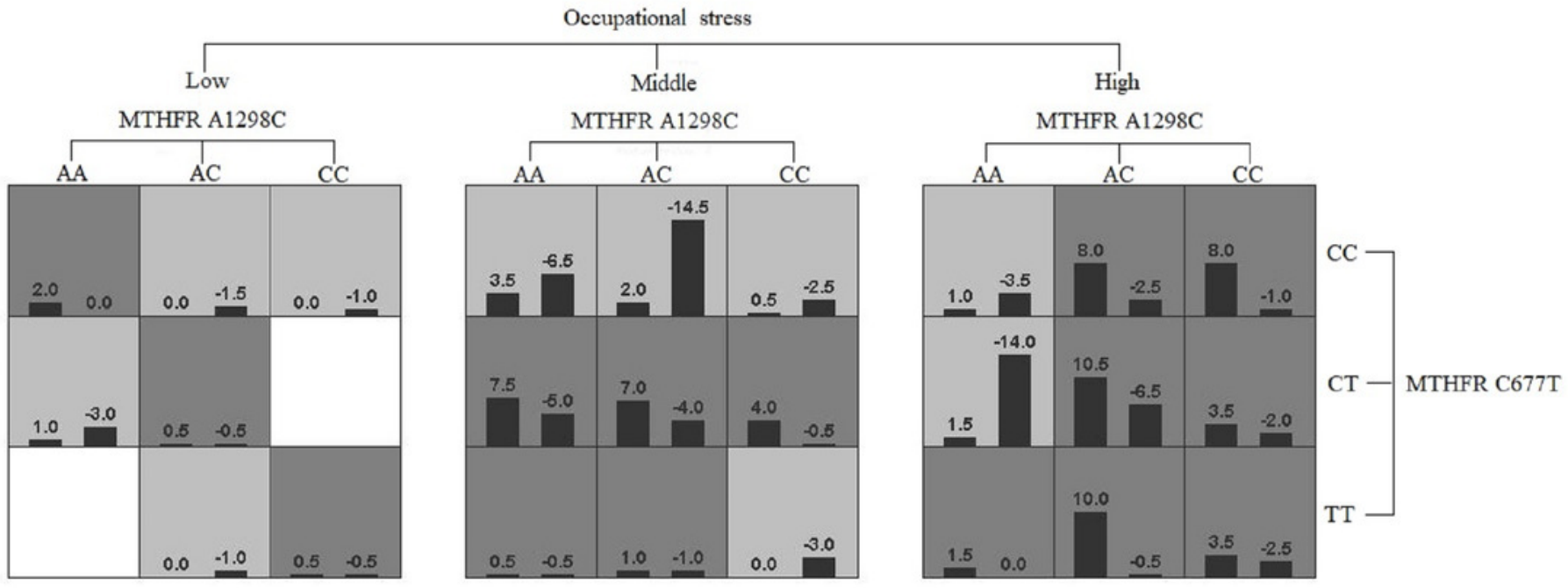


Figure 4

Gene-environment interaction model of MTHFR gene A1298C and C677T sites and occupational stress

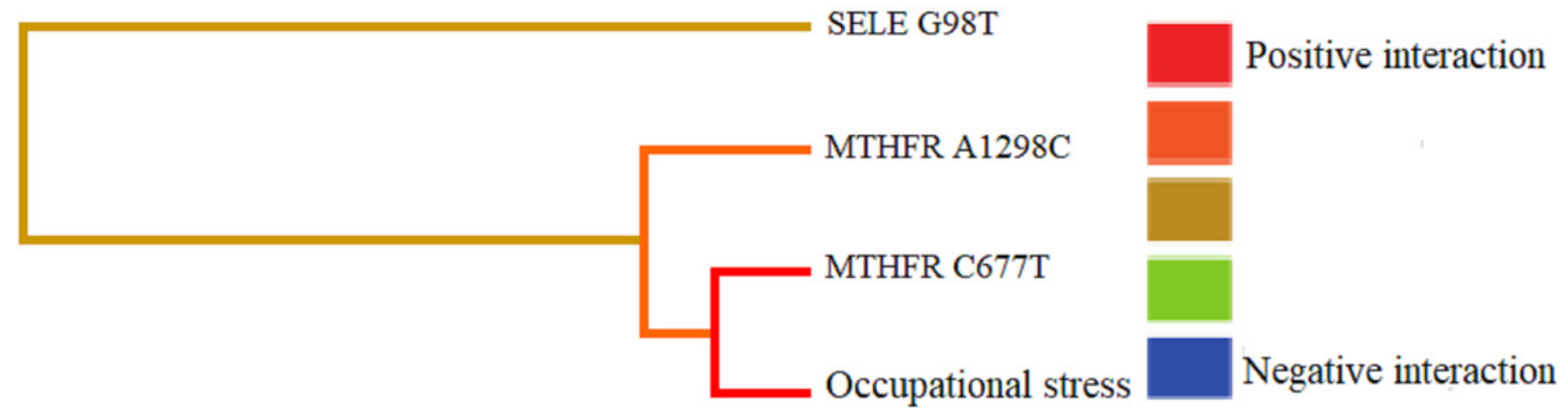

